\title{
LA DISLOCACIÓN A LA IZQUIERDA EN EL DISCURSO ESCRITO
}

\author{
MERCEDES SEDANO \\ Universidad Central de Venezuela \\ msedanog@yahoo.es
}

\begin{abstract}
Resumen
En este artículo se estudia el funcionamiento en el discurso escrito de la construcción denominada dislocación a la izquierda (DI), ilustrada en a este hombre lo veo bailando frecuentemente. Pragmáticamente, la DI está formada por un tópico (a este hombre) y una cláusula, considerada el comentario sobre el tópico (lo veo bailando frecuentemente), que contiene una copia (lo $)$ de éste. El corpus consta de 204 casos de DI encontrados en dos novelas de escritores españoles publicadas este siglo. Los parámetros estudiados son el tipo de información transmitida por el tópico, y las funciones discursivas de la DI. Los resultados más relevantes indican, por un lado, que el tópico suele contener información evocada -aunque también hay casos de información inferible e incluso nueva- $y$, por el otro, que entre las principales funciones discursivas de la DI está la que he denominado facilitadora del adecuado procesamiento del discurso, relacionada con la función simplificadora de Prince (1997), así como la de continuidad temática.
\end{abstract}

PALABRAS CLAVE: dislocación, pragmática, tópico, comentario.

\begin{abstract}
This paper analyzes the use in written discourse of the construction named leftdislocation (LD), illustrated in ... a este hombre lo veo bailando frecuentemente (...this man I see him dancing frequently). Pragmatically, LD is formed by a topic (a este hombre/ this man) and a clause, taken as the comment about the topic (lo veo bailando frecuentemente/ I see him dancing frequently), which contains a topic's copy ( $\underline{\mathrm{lo}} / \underline{\mathrm{him}})$. The corpus is formed by 204 LD occurrences found in two novels of Spanish writers published in this century. The parameters studied are the kind of information conveyed by the topic and the LD discourse functions. The most relevant results show that, on the one hand, the topic usually contains evoked information -although there are also cases of inferable and even new information- and, on the other hand, that among the LD main discourse functions figures the one I have called adequate discourse processing facilitator -related with Prince's (1997) simplifying function-, besides that of marking the thematic continuity.

KEY WORDS: dislocation, pragmatics, topic, comment.
\end{abstract}




\section{Introducción ${ }^{\star}$}

En este artículo se analiza el funcionamiento en el discurso escrito de la construcción denominada dislocación a la izquierda $(\mathrm{DI})^{1}$ para determinar hasta qué punto lo que se ha dicho sobre ella queda corroborado o no por los datos empíricos.

Se suele considerar que la DI, además de presentar características prosódicas particulares $^{2}$, se utiliza como un recurso pragmático para dividir una construcción en dos partes: en la primera está el tópico, que es el constituyente sobre el que trata el resto de la predicación; en la segunda está una cláusula considerada el comentario (por eso se la identifica de ahora en adelante como cláusula/comentario), que se define como lo que se dice sobre el tópico (Reinhart, 1982: 9; Barnes, 1985: 220)3). El tópico suele ser un sintagma nominal (SN) o equivalente, o bien un sintagma preposicional (SP). Está representado dentro de la cláusula/comentario por una copia, que generalmente es un pronombre clítico, aunque también puede ser un elemento nulo (null element, Lambrecht, 2001: 1056). ${ }^{4}$ Entre el tópico y la cláusula/comentario es posible encontrar una pausa entonativa, representada gráficamente por una coma, pero ésta no es una condición necesaria ${ }^{5}$. En (1) se ofrece un ejemplo prototípico de dislocación a la izquierda en español:

${ }^{\star}$ Deseo expresar mi profunda gratitud a Paola Bentivoglio por su atenta lectura de una versión anterior de este trabajo. Está de más decir que los errores que en él pueda haber son desde luego de mi entera responsabilidad.

${ }^{1}$ Este artículo es una continuación de Sedano (2011), dedicado a algunos aspectos formales de la DI. La introducción de ambos trabajos tiene algunas cosas en común, pero el resto, por supuesto, no las tiene.

${ }^{2}$ Para el español, véanse, entre otros, Hidalgo (2003: 134-138), Padilla García (2005) y Martín Butragueño (2008).

${ }^{3}$ Sobre los conceptos de tópico y comentario, cf., por ejemplo, Barnes (1985), Vallduví (1994) o Lambrecht (1998).

${ }^{4}$ El elemento nulo se suele dar cuando el tópico funciona como sujeto (cf. el ejemplo (3), más adelante). Aunque estoy de acuerdo con Hidalgo (2003: 159) cuando dice que la tematización del sujeto en español se manifiesta a través de la concordancia verbal, a lo largo de este trabajo, y para facilitar la exposición, colocaré el símbolo $\varnothing$ en el lugar que correspondería originalmente a un sujeto que sufre dislocación a la izquierda. Esa marca Ø representa a la copia nula.

${ }^{5}$ Cf. Dik (1978: 153, 155), Givón (1990: 759), Lambrecht (2001: 1050), Padilla García (2005: 120-121). Es importante señalar, sin embargo, que Sedano (2011) observa que, en el corpus empleado en esa investigación (el mismo que se utiliza en ésta), apenas hay casos de DI en los que una coma (equivalente a una pausa en la lengua hablada) separe el tópico de la cláusula/comentario. 


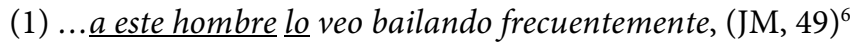

La construcción anterior cuenta con un tópico situado en el extremo izquierdo, a este hombre ${ }^{7}$, y una cláusula (lo veo bailando frecuentemente) que da información sobre el tópico. El tópico tiene por copia el clítico $\underline{\underline{l o}}$, que funciona como complemento directo en la cláusula/comentario ${ }^{8}$.

Estructuralmente, el hecho de que una entidad se presente como tópico de una DI hace que se éste se interprete como la entidad sobre la que se añade información en la cláusula/comentario. Esa interpretación determina que no sea pragmáticamente adecuado poner cualquier constituyente en la posición de tópico (cf. \$3.1.).

La principal característica de la DI es el carácter extraclausular y optativo del tópico (Jiménez Julia, 2000: 156; Lambrecht, 2001: 1065). Esto significa que se podría eliminar este constituyente sin que ello generara ningún tipo de agramaticalidad en la cláusula subsiguiente (lo veo bailando frecuentemente).

La DI tiene una contraparte, llamada dislocación a la derecha, que, volviendo al ejemplo de (1), sería Lo veo bailando frecuentemente, a este hombre. Parece demostrado que ambos tipos de construcciones, a pesar de su semejanza formal, cumplen funciones pragmáticas muy diferentes (Lambrecht, 2001: 1051; Martín Butragueño, 2010).

La DI se diferencia también de otras dos construcciones del español. La primera es la llamada topicalización (Lambrecht 2001: 1052; Prince 1985: 67) ( eso se decía, JM, 42), que se distingue de la DI en que, mientras el tópico de la DI es un constituyente extraclausular, en la topicalización forma parte de la misma cláusula ya que no hay ninguna copia que lo represente. La segunda construcción, denominada anteposición de foco (“Ochenta mil pesos dice que le dieron...", Silva-Corvalán, 1984: 12), se caracteriza por la posición oracional inicial de un constituyente normalmente posverbal para presentarlo como foco de contraste o foco contraesperado. Esta construcción se diferencia de la DI por el contexto y desde luego por la prosodia: cabe señalar, entre otras cosas, que

\footnotetext{
${ }^{6}$ Los ejemplos extraídos del corpus que aparecen en este artículo van seguidos por una información entre paréntesis con las iniciales del autor (JM = Javier Marías; AS = Antonio Soler) y el número de página donde está el ejemplo. El tópico y su copia se presentan subrayados en los ejemplos.

${ }^{7}$ En la nota 6 ya se dijo que en el presente trabajo se subraya el constituyente tópico. Sin embargo, desde el punto de vista teórico, es importante diferenciar ese constituyente (que en el ejemplo (1) es el $\mathrm{SN}$ a este hombre) de la entidad discursiva que funciona realmente como tópico; en el caso de (1), dicha entidad es el referente de este hombre.

${ }^{8}$ Aunque el elemento que verdaderamente ejerce una función sintáctica en la cláusula es la copia, si tomamos en cuenta que ésta es correferencial con el tópico, en ocasiones haré mención de la función sintáctica del tópico para referirme en realidad a la función sintáctica de la copia.
} 
el pico entonativo es mucho más elevado en el constituyente focal de la Anteposición de foco que en el constituyente tópico de la DI.

Hay testimonios de que las cláusulas de dislocación a la izquierda se emplean en muchas lenguas del mundo, lo cual justifica su estudio". Entre las muchas interrogantes que plantea la DI están el tipo de información que transmite el tópico y cómo se emplea la DI en el discurso. En este artículo se pretende dar una respuesta, aunque sea parcial, a estas preguntas.

\section{Corpus y metodología}

El estudio se ha realizado tomando en cuenta los casos de DI encontrados en dos obras narrativas del español publicadas a principios del siglo XXI: Tu rostro mañana (1. Fiebre y lanza), de Javier Marías, y El camino de los ingleses, de Antonio Soler ${ }^{10}$. He escogido dos escritores con el fin de que, por encima de las diferencias estilísticas de cada uno de ellos, puedan aflorar las características discursivas propias de la DI.

Para el análisis de la DI he seleccionado aquellas construcciones que presentan la estructura ilustrada en (1), es decir, las que tienen en el extremo izquierdo un constituyente extraclausular considerado el tópico que precede a una cláusula en la que hay una copia (pronominal o $\varnothing$ ) de ese constituyente.

La presencia de la copia es evidente cuando ésta funciona como complemento directo de la cláusula $(1)^{11}$, o bien como complemento indirecto $(2)^{12}$ :

\footnotetext{
9 La DI se emplea, entre muchas otras muchas lenguas, en árabe clásico, catalán, español, francés, inglés, italiano, japonés y mandarín (Barnes, 1985; Vallduví, 1994; Lambrecht, 2001; Hidalgo, 2003).

${ }^{10}$ El narrador de la obra de J. Marías es un español radicado en Londres que tiene el don de saber interpretar adecuadamente los gestos y palabras de los demás. Por poseer ese don es contratado por una agencia de inteligencia. En la obra de A. Soler se narra el último verano de un grupo de adolescentes que después se separan para emprender su vida de adultos.

${ }^{11}$ A diferencia de otros autores, Padilla García (2005: 118) considera que la DI se caracteriza "por afectar exclusivamente a los objetos".

${ }^{12}$ Algunos autores (Lambrecht, 2001: 1053; Hidalgo, 2003: 171-173, entre otros) consideran que las construcciones de duplicación del complemento indirecto no deberían considerarse casos de DI, ya que se emplean más por requerimientos de la gramática que del discurso. En la presente investigación analizo esas construcciones como de DI si el complemento indirecto está en posición inicial. Lo hago, en primer lugar, porque en una oración como $\underline{\text { A Juan }}$ le perjudica mucho este clima, podría suprimirse el constituyente $\underline{A \text { Juan }}$ y la oración seguiría siendo gramatical (Le perjudica mucho este clima) y, en segundo lugar, porque $\underline{\text { A Juan }}$ podría haber aparecido en otra posición y no ya al inicio (Este clima le perjudica mucho a Juan; Este clima a Juan le perjudica mucho), de manera que su anteposición, cuando se da, es optativa y obedece a una necesidad comunicativa particular. Cabe señalar además que la
} 
(2) ... a la Gorda de la Cala el aliento le olía a gas butano. (AS, 41)

También se incluyen en el análisis las construcciones como (3):

(3) Arias, que es como se llamaba aquel hombre, $\underline{\emptyset}$ se habia ido acercando cada vez más... (AS, 284)

En la construcción anterior hay un material intermedio (que es como se llamaba aquel hombre) entre el tópico ( $\underline{\text { Arias }}$ y una cláusula/comentario en la cual la copia del tópico es un elemento nulo $\underline{\varnothing}$ que funciona como sujeto ${ }^{13}$.

Se habrían incluido asimismo en el análisis aquellos casos de DI en los que tanto el contexto como la presencia de una coma después del tópico hubieran permitido inter-

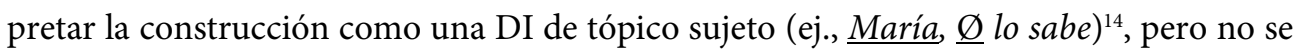
ha hallado ningún caso ${ }^{15}$.

En el corpus se han registrado 90 construcciones de DI en la obra de Javier Marías y 114 en la de Antonio Soler, lo que hace un total de $204^{16}$. El hecho de que seis de esas construcciones contengan dos tópicos (Sedano, 2011) condiciona cuantitativa-mente el análisis de la sección 3 , que se realiza sobre 210 tópicos, con sus copias correspondientes.

\footnotetext{
presencia del clítico no sólo es obligatoria con el complemento indirecto sino también con el complemento directo cuando este aparece antepuesto ( ${ }^{\star}$ Ese libro compramos ayer muy barato $\rightarrow$ Ese libro LO compramos ayer muy barato). Finalmente, conviene tener presente que si se rechaza a priori la posibilidad de estudiar la DI con un copia que funciona como complemento indirecto, no se podrá saber con certeza si se justifica empíricamente su exclusión.

${ }^{13}$ Sobre la conveniencia de incluir este tipo de casos en el estudio de la DI, véanse, entre otros, Ashby (1988), Aijmer (1989) e Hidalgo (2003).

${ }^{14}$ Conviene recordar que una oración como María lo sabe puede interpretarse como formada sintácticamente por sujeto (María) y predicado (lo sabe), pero también como una construcción de foco marcado (MARÍA, lo sabe) o bien de tópico marcado (María $\underline{\emptyset}$ lo sabe); en este último caso se trataría de una DI. Sobre la ambigüedad de una construcción como María lo sabe, cf., entre otros, Gregory y Michaelis (2001: 1670) y Lambrecht (2001: 1056). Sobre los conceptos de tópico y foco, véanse, por ejemplo, Lambrecht (1998) y Gutiérrez Ordóñez (2000).

${ }^{15}$ Sobre el reducido uso en el presente corpus de la DI para topicalizar sujetos, véase Sedano (2011).

${ }^{16}$ Esta cantidad de casos permite pensar que la DI no sólo se da en el habla informal y poco planificada, como señalan algunos autores, sino también en la escritura formal, lo cual la ratifica como un recurso discursivo de nuestro idioma.
} 
A lo largo de este artículo, y para simplificar la exposición, se analizan conjuntamente las construcciones seleccionadas de los dos escritores del corpus, aunque es evidente que cada uno de ellos suele mostrar preferencia por un determinado tipo de $\mathrm{DI}^{17}$.

En la secciones siguientes se analizan las estructuras de DI halladas en el corpus a la luz de varios parámetros discursivos que han sido tomados en consideración en los estudios realizados hasta ahora. En la sección 3 se estudia el tipo de información transmitida por el tópico; en la sección 4, las funciones comunicativas de la DI y, en la sección 5 , el empleo de la DI en la estructura temática del discurso.

\section{Tipo de información transmitida por la entidad que funciona como tópico}

El concepto de información asociada a una entidad del discurso varía dependiendo de las clasificaciones hechas por los distintos autores. En el presente artículo me baso en Prince (1981), quien clasifica las entidades del discurso según el grado de familiaridad que, a juicio del emisor, puede tener con ellas el receptor.

\subsection{Tópico con información evocada}

Una entidad se considera evocada ${ }^{18}$ si ya ha sido mencionada en el discurso inmediato previo (evocada en el texto) o si está presente en la situación de habla (evocada en la situación $)^{19}$. En (4a-b) se ilustran dos tópicos evocados en el texto y en (4c) se hace otro tanto con un tópico evocado en la situación. Los tópicos y sus copias aparecen subrayados, como se ha hecho a lo largo del presente artículo; la letra negrita sirve para identificar una información del discurso previo que, en términos generales, puede considerarse el antecedente del tópico, el elemento con el que éste se relaciona de una u otra forma:

(4) a. Y en cuanto a destruirla más tarde, comprendo que eso tampoco lo hiciera, (JM, 209)

b. Así vieron a la mujer que había tirada en el jardín de la casa de Paco Frontón [10 líneas de texto]. Y después de que él gritara desde el andamio y de que el jefe

\footnotetext{
${ }^{17}$ J. Marías, por ejemplo, topicaliza frecuentemente pronombres demostrativos para sintetizar el contenido de una proposición previa, en tanto que A. Soler es muy aficionado a topicalizar nombres propios para dar relevancia temática a los personajes de su novela.

${ }^{18}$ Algunos autores, por ejemplo, Chafe (1994:73-74), hablan de información dada (given) en vez de información evocada (evoked). En el presente artículo considero que esos dos términos son más o menos sinónimos.

${ }^{19}$ Las referencias a los interlocutores (yo, tú) se suelen considerar información evocada.
} 
de obras aporreara la puerta de la casa, a aquella mujer la vieron casi todos los habitantes del barrio, (AS, 157)

c. Y uno se sorprende diciéndose casi sin querer [...]: 'Me cae bien', 'A ese tipo no lo aguanto', 'Me la comería a besos'. (JM, 266)

En (4a) el pronombre demostrativo eso es información evocada porque se relaciona anafóricamente con la cláusula infinitiva precedente, destruirla más tarde. En (4b), el tópico a aquella mujer es también información evocada porque se interpreta como co-

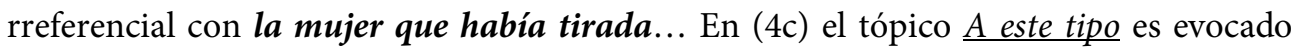
situacionalmente porque el narrador dice esa frase imaginando que está viendo a un tipo particular en una determinada situación de habla ${ }^{20}$.

\subsection{Tópico con información inferible}

Una entidad es inferible si se asocia directamente a una idea que es o fue activada en el contexto previo. En (5a-b) se ofrecen dos ejemplos ilustrativos:

(5) a. Hay una obsesión por comprender lo odioso, en el fondo hay una malsana satisfacción por ello, y a los odiosos se les hace con ello un inmenso favor. (JM, 217)

b. El maquillaje de los ojos [4 líneas de texto]. Los labios, que parecían blandos, también los llevaba pintados de un color parecido. El casco era de caoba. (AS, 67)

En (5a) el tópico a los odiosos, aunque no se ha mencionado previamente, se relaciona con la nominalización genérica de lo odioso situada en una cláusula anterior, de ahí que se considere inferible. En (5b) se está describiendo la apariencia física de una determinada mujer; al mencionar el maquillaje de los ojos se está creando un marco discursivo en el que pueden entrar los ojos, los labios, el pelo (en el texto lo llaman casco); esto hace que el tópico los labios pueda considerarse también inferible.

\subsection{Tópico con información nueva}

Una entidad es nueva en el discurso si el emisor cree que la está activando en la conciencia del receptor en el momento del acto de habla. Según Prince (1981), este tipo de información puede ser totalmente nueva ${ }^{21} \mathrm{o}$ bien nueva no usada ${ }^{22}$.

\footnotetext{
${ }^{20}$ Se trata de un caso especial (de hecho, el único en el corpus) porque refleja una situación virtual.

${ }^{21}$ Una entidad totalmente nueva es aquella que el emisor supone que el receptor no puede identificar en el momento del acto de habla. Puede estar anclada en el discurso (se relaciona con alguna entidad que ha sido mencionada en el discurso inmediato previo o está presente en la situación de habla) o no anclada (cuando no hay marcas de anclaje).
} 
En el corpus, los pocos casos de DI cuyo tópico contiene información nueva presentan características particulares. Veamos en primer lugar los ejemplos (6a-b):

(6) a. El primer golpe de karate se lo dio Amadeo a su abuelo el día que al entrar en el dormitorio común el viejo se quedó muy serio mirando los pósteres de Bruce Lee... (AS, 52)

b. El palo con el que golpeó la cara del enano lo debió de encontrar en el trayecto... (AS, 310)

En (6a), el tópico El primer golpe de karate, que aparece al inicio de un párrafo, cuenta con el sustantivo El primer golpe, que contiene información totalmente nueva porque ese golpe no se ha mencionado antes en la obra. Sin embargo, ese sustantivo está modificado por la frase preposicional de karate; conviene señalar al respecto que varias páginas antes se ha dicho de pasada que Amadeo practicaba karate. Además, toda la construcción de DI es coherente con la información suministrada en el párrafo anterior, donde se dice que al nieto le gustaba molestar al abuelo.

En (6b), el tópico El palo con el que golpeó la cara del enano tiene por núcleo El palo, que contiene también información totalmente nueva, porque no se mencionado antes ese objeto y podría haber sido cualquier otro: una barra de metal, una piedra, un ladrillo, etc. Sin embargo, dicho núcleo va acompañado por una relativa (con el que golpeó la cara del enano) cuya información ya ha sido evocada.

Obsérvese entonces que tanto en (6a) como en (6b) el tópico, aunque nuevo, está modificado por un complemento (de karate en (6a); con el que golpeó la cara al enano en (6b)) asociado a una información que el lector ya debería conocer.

Para poner un último ejemplo de los casos de información nueva encontrados en el corpus, veamos más adelante en (9) que el tópico a un tío mío es totalmente nuevo, si bien está anclado a la persona del narrador, lo cual facilita su reconocimiento como tópico.

En (7a-b) se ofrecen dos ejemplos de información nueva no usada:

(7) a. Al enano Martínez lo soltaron a los dos días de haberlo detenido. (AS, 346)

b. A Avelino Moratalla le perdí la pista. (AS, 347)

En los dos casos, la construcción de DI en la que aparecen ambos tópicos (Al enano

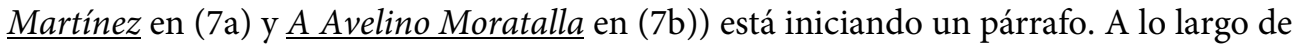

\footnotetext{
${ }^{22}$ Una entidad nueva no usada es aquella que el emisor supone que el receptor puede identificar, pero que no ha sido mencionada en el contexto inmediato previo ni está presente en la situación de habla, por lo tanto, el receptor no la tiene en su conciencia en el momento del acto de habla.
} 
la obra, se ha hecho repetida referencia a esos personajes. Sin embargo, no se los menciona en los dos párrafos que preceden al párrafo en el que aparecen ${ }^{23}$, por lo tanto, les asigno el estatus de información nueva no usada, lo cual significa que son entidades que el lector de la obra puede identificar pero que no están en su foco de conciencia en el momento en que aparecen en el texto.

\subsection{Resultados del análisis sobre la información transmitida por el tópico}

En el cuadro 1 se ofrecen los resultados sobre el tipo de información transmitida por el tópico:

\begin{tabular}{|l|c|c|}
\cline { 2 - 3 } \multicolumn{1}{c|}{} & Casos & $\%$ \\
\hline Evocada & 144 & 68,57 \\
\hline Inferible & 55 & 26,19 \\
\hline Nueva & 11 & 5,23 \\
\hline Total & 210 & 100 \\
\hline
\end{tabular}

Cuadro 1. Información transmitida por el tópico

Estos datos indican que lo más frecuente en el corpus es que el tópico transmita información evocada (68,57\%), aunque también hay casos en que transmite información inferible $(26,19 \%)$ e incluso nueva $(5,23 \%)^{24}$.

La información evocada, salvo en el ejemplo al que se había hecho referencia en (4c), es siempre evocada en el texto. En cuanto a la información nueva, no parece que ésta sea radicalmente nueva: o bien está modificada por un complemento que contiene información evocada, como en (6a-b), o bien está anclada a algún personaje del discurso como en (9), o bien hace referencia a entidades que se han mencionado en el discurso previo, aunque haya sido a considerable distancia, como en (7a-b).

\footnotetext{
${ }^{23}$ Chafe (1994) considera que una entidad a la que deja de hacerse referencia en el texto cambia pronto su estatus informativo. En la presente investigación considero que una entidad pasa de ser evocada en el texto a nueva no usada si no se ha mencionado en los dos párrafos precedentes. Estoy consciente, sin embargo, de que esta decisión es subjetiva y que, por lo tanto el estatus informativo asignado a una determinada entidad del discurso puede variar un poco dependiendo de los criterios empleados por cada investigador.

${ }^{24}$ Hago notar que los porcentajes sobre información inferible y nueva reflejan una percepción en algunos casos subjetiva de la información transmitida por las entidades que funcionan como tópico.
} 
Hidalgo (2003: 212), en su estudio sobre el tema antepuesto en el español hablado ${ }^{25}$, analiza sólo los temas léxicos, y ofrece los siguientes porcentajes por tipo de información: dada (46,99\%), inferible (33,46\%), nueva $(13,91 \%)$, y dudosa $(5,64 \%)^{26}$. El hecho de que en estos datos no se hayan incluido los pronombres, que la autora considera fundamentalmente transmisores de información dada/evocada, nos permite pensar que sus resultados muestran tendencias en cierta medida similares a las de la presente investigación.

Martín Butragueño (2010: 169) obtiene los siguientes porcentajes en su estudio del tipo de información del tema antepuesto: dada (70\%), inferible (13\%), nueva (17\%). El que este investigador obtenga proporcionalmente más casos de información nueva que inferible es posible que se deba al tipo de corpus, pero también a la subjetividad que rodea el establecimiento de los límites entre la información inferible y la nueva. En cualquier caso, lo que tienen en común los resultados del mencionado investigador y los del presente análisis es que los tópicos que transmiten información evocada superan considerablemente a los que transmiten información inferible y nueva.

Los resultados del presente corpus con respecto al tipo de información transmitida por el tópico confirman en cierta medida lo afirmado por Padilla García (2005), quien señala que, por lo general el tópico de la dislocación a la izquierda en español suele ser [-nuevo].

\section{Funciones discursivas de la dislocación a la izquierda}

Los investigadores que han estudiado la DI suelen hacer referencia a las distintas funciones discursivas que puede tener esta construcción. En la presente sección analizaré algunas de dichas funciones a la luz de los datos del corpus. No se cuantifican los resultados, por un lado, porque las funciones de la DI encontradas no son necesariamente excluyentes y, por otro lado, porque es imposible eliminar una cierta dosis de subjetividad en el análisis.

Los tres primeros apartados de esta sección están destinados a evaluar los criterios propuestos por Prince (1997), lingüista según la cual la DI, al menos en inglés, desarrolla fundamentalmente tres funciones discursivas: i) Simplificar el proceso del discurso

\footnotetext{
${ }^{25}$ Hidalgo (2003) y Martín Butragueño (2010) denominan a la construcción de DI de tema antepuesto. El tema equivale al término tópico empleado en el presente artículo.

${ }^{26}$ Esta autora, al igual que Martín Butragueño (2010) y que yo misma, sigue a Prince (1981) en su división de los tipos de información.
} 
(Simplify discourse processing); ii) Desencadenar una inferencia poset (Trigger a parcially ordered set); iii) Lograr la amnistía de una violación de isla mediante el uso de un pronombre reasuntivo (Amnesty an island-violation: resumptive pronoun). Snider (2005) y Manetta (2007), entre otros, parecen comprobar el empleo de las dos primeras funciones propuestas por Prince, al menos en los corpus del inglés estudiados por esos investigadores. Analicemos ahora si esas funciones se dan también en el español.

\subsection{Función simplificadora}

Esta función se da, según Prince (1997: 123), cuando se topicaliza una frase nominal discursivamente nueva, la cual, si estuviera en una oración no dislocada aparecería en una posición poco apropiada para las entidades nuevas. La mencionada autora considera que este es el caso, sobre todo, de los tópicos nuevos que funcionan como sujetos en inglés. ¿Por qué sucede esto?

Dado que habitualmente los sujetos, sobre todo en inglés, se asocian a información dada, la presencia de un sujeto nuevo va en contra de las expectativas del oyente; en cambio, si ese sujeto se emplea como tópico en una estructura de DI se lleva a efecto, según Prince, una función simplificadora: la posición de tópico de una DI hace que esa entidad nueva no se procese propiamente como sujeto sino como tópico. En esas condiciones, cuando aparece la copia del tópico en la cláusula/comentario, dicha copia tiene ya la forma de un pronombre que transmite información evocada, lo cual es característico de los sujetos.

En el presente corpus se constata el uso de la función simplificadora, pero no ya cuando el tópico es sujeto y transmite información nueva (en los pocos casos encontrados de DI con tópico sujeto, dicho tópico transmite información evocada ${ }^{27}$, sino en muchos otros casos, sobre todo cuando el tópico es léxico y se desempeña como complemento directo, que es la función sintáctica más frecuente en el corpus. En cuanto al tipo de información contenida por ese tópico, no es necesario que sea nueva. Veamos en (8) un ejemplo de un tópico complemento directo que contiene información evocada. El antecedente de ese tópico y sus referencias subsiguientes aparecen en negritas:

(8) Más de una vez se me dijo que era un don que tenía [el de saber interpretar las palabras y gestos de los demás] y así me lo mostró Peter Wheeler, que fue quien

\footnotetext{
${ }^{27}$ En el corpus empleado por Sedano (2011), que es el mismo utilizado en esta investigación, hay 136 tópicos que funcionan como complemento directo $(64,76 \%), 62$ que funcionan como complemento indirecto $(29,52 \%)$ y tan sólo 12 que funcionan como sujeto $(5,71 \%)$.
} 
me alertó al explicármelo y describírmelo, las cosas no acaban de existir hasta que se las nombra, eso todo el mundo lo sabe o lo intuye. Ese don yo lo veo en cambio como una maldición a veces, (JM, 27)

El tópico Ese don de (8) ya se ha mencionado antes en el discurso. En lugar de la DI el escritor podría haber empleado una oración normal, no topicalizadora, con el complemento directo léxico en posición postverbal (Yo veo en cambio ese don como una maldición a veces), que es la posición habitual para ese tipo de complemento. Ahora bien, en esa posición, el complemento directo podría haberse interpretado como el foco de la oración o, al menos, como parte del foco. Si el escritor quiere evitar esa interpretación porque desea dar relevancia temática a Ese don, debe colocarlo en la posición inicial de una DI.

Es importante hacer notar que, en (8), entre Ese don y la última mención de su antecedente (describirmelo) hay varias cláusulas (las cosas no acaban de existir hasta que se las nombra, eso todo el mundo lo sabe o lo intuye) que cortan la continuidad temática. La interposición de esas cláusulas seguramente influye también para que Ese don aparezca en una DI, construcción esta que estimula al lector a establecer las relaciones temáticas discursivas que el emisor desea.

Veamos ahora en (9) otro caso de tópico léxico que funciona como complemento directo. En este caso, el tópico contiene información nueva:

(9) Y sin embargo mi padre había estado a punto de morir [en la guerra] con el uniforme de la República en nuestra ciudad asediada, y había sufrido a su término simulacro de proceso y prisión franquistas, y a un tío mío lo habían matado en Madrid a los diecisiete años y a sangre fría los del otro bando -el bando partido en tantos, lleno así de calumnias y purgas-, los milicianos sin control ni uniforme que daban el paseo a cualquiera... (JM, 90)

En la DI de (9), el tópico a un tío mío se refiere a una entidad que no ha sido evocada en el discurso previo, si bien está anclada al narrador por el posesivo mío. Ese tópico tiene una copia (lo $)$ que funciona como complemento directo. Si, en vez de una DI se hubiera empleado una oración declarativa normal con el complemento directo en posición postverbal ( $y$ habían matado a un tío mío en Madrid a los diecisiete años y a sangre fría los del otro bando), ese complemento se interpretaría, a causa de su carácter indeterminado, como parte del foco oracional y, en consecuencia, no se establecería un paralelismo temático entre los dos tópicos del párrafo (mi padre / un tío mío). Debido a ello, la oración resultante se relacionaría muy mal con el discurso precedente porque perdería toda coherencia discursiva.

Los ejemplos (8) y (9) ilustran el cumplimiento en el corpus de una función discursiva de la DI que consiste en presentar la información de tal forma que ayude al recep- 
tor a hacer las conexiones e interpretaciones temáticas adecuadas. Propongo denominar esta función facilitadora del adecuado procesamiento de la información. Esta función se relaciona desde luego con la función simplificadora a la que hace referencia Prince (1997), pero presenta importantes diferencias, quizá debidas a que esa investigadora estudia fundamentalmente la DI del inglés: mientras Prince considera que la función simplificadora de la DI se da cuando el tópico contiene información nueva y, por ello, resulta poco o nada compatible, en una oración normal, con ciertas funciones sintácticas, sobre todo con la de sujeto, la función facilitadora... se da en el presente corpus cuando el tópico es léxico y se desempeña fundamentalmente como complemento directo. Aunque los datos indican que el tópico puede contener cualquier tipo de información, es obvio que cuando contiene información nueva o inferible, la función facilitadora se ejerce con mayor propiedad porque es en esos casos cuando mayor es la posibilidad de interpretar equivocadamente el complemento directo como parte del foco. $\mathrm{Al}$ emplear una DI con el complemento directo léxico como tópico (en cualquier circunstancia, pero sobre todo si es nuevo o inferible), se anula la posibilidad de interpretarlo como foco o parte del foco y, por lo tanto, se estimula al receptor a hacer las conexiones temáticas correspondientes.

\subsection{Función de inferencia poset}

Según Prince (1997: 126), una DI de este tipo ejerce esa función cuando la entidad correspondiente al tópico pertenece a un conjunto parcialmente ordenado con respecto a otra entidad del discurso previo. Esta circunstancia sirve para desencadenar una inferencia por parte del oyente.

Aunque, según la mencionada autora, la inferencia poset parece darse cuando el tópico constituye información dada, los casos más claros de ese tipo de inferencia los encuentro en el corpus en los tópicos que transmiten información inferible. En (10a-b), a continuación, presento dos ejemplos que muestran ese tipo de inferencia:

(10) a. Me pareció una mujer desde el primer instante, y lo era, porque tras un segundo o resquicio de duda me gustaron sus piernas [4 líneas más de texto]. El rostro le quedaba oculto por la copa de su paraguas, ambas manos las tenía ocupadas, (JM, 369)

b. Las montañas de las revistas de artes marciales que tenía alineadas contra la pared debian tener 30 centímetros exactos de altura. 45 revistas por montaña. Los números extra los miraba detenidamente en el quiosco del Carne, pero no los compraba para que no le desequilibraran la perfecta simetría de la habitación. (AS, 52) 
En (10a), el tópico ambas manos se relaciona con el rostro y con sus piernas, mencionados previamente, puesto que todos ellos forman parte del conjunto que representa el cuerpo de la mujer. En (10b), los números extra también forman parte del conjunto formado por las revistas de artes marciales mencionadas poco antes.

A modo de conclusión puede decirse que la función de inferencia poset a la que hace referencia Prince (1997) sí se registra en el corpus, aunque no es cuantitativamente muy frecuente. Como ya dije, los casos más evidentes de ese tipo de inferencia se dan cuando el tópico constituye información inferible.

\subsection{Función de amnistía de una violación de isla (Amnesty an Island-Violation)}

Prince (1997: 132) dice que la DI cumple esta función cuando la extracción del sustantivo que pertenece a una determinada cláusula (una relativa, por ejemplo) para anteponerlo y convertirlo en tópico deja un vacío sintácticamente inadecuado. El hablante llena ese vacío con un reasuntivo esclarecedor a fin de representar al tópico de la forma más icónica posible dentro de su propia cláusula. La presencia del reasuntivo da lugar a una oración comprensible, si bien alejada de las reglas de gramática del idioma ${ }^{28}$. Aunque seguramente en el español oral sí se da este tipo de DI, sobre todo cuando el tópico tiene una forma absoluta (ej., María, yo me di cuenta de que la nota que había escrito para ella nunca llegó a sus manos $)^{29}$, no se ha encontrado ningún caso en el corpus.

\subsection{Contraste}

Chafe (1976) considera que una función importante de la DI es servir de contraste ${ }^{30}$; Geluykens (1992: 87) también da una gran relevancia a ese concepto en relación con la DI del inglés. Prince (1997) y Traugott (2007), por el contrario, observan que en sus corpus de DI apenas hay casos de contraste.

\footnotetext{
${ }^{28}$ Ziv (1994: 237) llama a esa función terapéutica porque considera que ayuda a restaurar la configuración gramatical de la cláusula. Este autor ofrece los siguientes ejemplos (p. 638), adaptados de Prince, donde la copia it al final de la segunda cláusula es el reasuntivo utilizado para evitar el vacío de la

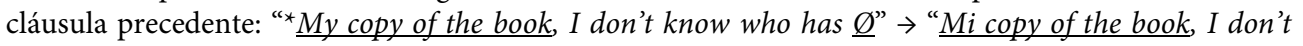
know who has it".

${ }^{29}$ Es decir, cuando no hay marca de su función sintáctica en la copia (es lo que sucede en el caso de María con respecto a su copia para ella).

${ }^{30}$ Según Silva-Corvalán (1984: 8), hay contraste cuando un referente "se opone a un número limitado de alternativas que son claramente identificables como elementos de un mismo conjunto semántico".
} 
En los materiales estudiados en la presente investigación, los casos de verdadero contraste son muy raros. A continuación se ilustra uno de ellos, en el que la cantidad contrasta con el color $^{31}$ :

(11) A Avelino Moratalla no le importaba el color, a él sólo le interesaba la cantidad. (AS, 30)

Lo que sí se detecta, aunque en número limitado (no llegan a ocho casos), es lo que Barnes (1985) llama comparación, e Hidalgo (2003: 256) y Martín Butragueño (2010: 172), tema comparativo ${ }^{32}$. Veamos ejemplos ilustrativos en (12):

(12) a. La primera vez que Rafi se introdujo un destornillador por el agujero de la uretra al Carne le dio un mareo y a Avelino Moratalla se le saltaron las lágrimas (AS, 44)

b. Así como a Rylands lo frecuenté bastante, a Wheeler no lo vi hasta el final de aquella estancia mía, (JM, 33)

En estos ejemplos, hay una entidad del discurso involucrada en una acción o situación, y también hay una entidad "paralela" involucrada en una acción o situación también paralela. En (12a), por ejemplo, El Carne y Avelino Moratalla son dos entidades paralelas que se comportan de distinta manera en una determinada oportunidad: mientras al Carne le dio un mareo, a Avelino Moratalla se le saltaron las lágrimas.

\section{Empleo de la DI en la estructura temática del discurso}

La estructura temática del discurso se relaciona con la organización de los temas y subtemas de un discurso, los cuales están en buena medida asociados a las entidades presentadas como tópicos (marcados o no marcados) y a lo que se dice sobre ellas. La interrogante que nos plantea la DI es si esta construcción suele emplearse para introducir un tópico o para reintroducirlo, para mantener la continuidad temática, para iniciar un cambio temático progresivo, para cerrar un tema o bien como inciso.

\footnotetext{
${ }^{31}$ Obsérvese, sin embargo, que el contraste no afecta al tópico sino a un constituyente de la cláusula/comentario.

${ }^{32}$ Martín Butragueño (2010: 172) encuentra en su corpus 4\% de casos de tema comparativo y $7 \%$ casos de contraste.
} 


\subsection{Introducción o reintroducción de un tópico}

Varios de los autores que han estudiado el uso de de la DI consideran que esta construcción puede emplearse para introducir un tópico, o bien para reintroducirlo -cuando se supone que no está en la conciencia del oyente en el momento de la emisión, con la finalidad de seguir haciendo referencia a él (Geluykens 1992; Ziv 1994: 633). Con respecto a la reintroducción, Givón (1983: 32) señala que la DI puede usarse "to retun topics back into the register over long gaps of absence, thus high ref. distance, and also consequently fairly high potential interference values".

Hidalgo (2003), en su estudio del español oral, ofrece algún ejemplo de introducción y dice que los casos de reintroducción son esporádicos. Martín Butragueño (2010: 172) encuentra muy pocos casos de introducción en su corpus del español oral (1\%), y también pocos de reintroducción (3\%). Snider (2005), por su parte, no halla casos de reintroducción en su estudio del inglés.

En el presente corpus, seguramente por provenir del español literario, no se suele introducir abruptamente ningún tópico. La función introductora, sin embargo, aunque muy escasa en el corpus, se da en algunas construcciones de DI en las que el tópico tiene exclusivamente menciones posteriores, como sucedía en el ejemplo (6b) y (9), que se reproduce aquí como (13), con el contexto ampliado:

(13) Y sin embargo mi padre había estado a punto de morir [en la guerra] con el uniforme de la República en nuestra ciudad asediada, y había sufrido a su término simulacro de proceso y prisión franquistas, y a un tío mío lo habian matado en Madrid a los diecisiete años y a sangre fría los del otro bando -el bando partido en tantos, lleno así de calumnias y purgas-, los milicianos sin control ni uniforme que daban el paseo a cualquiera, lo habían matado por nada a la edad en que casi sólo se fantasea y no hay más que ensueños, y su hermana mayor, mi madre, había buscado su cadáver por esa misma ciudad sitiada sin encontrarlo, sólo la burocrática y minúscula foto de ese cadáver, (JM, 90)

En este fragmento, se introduce, mediante la DI, el tópico a un tío mío, y se sigue hablando de él después. Las menciones subsiguientes aparecen en negritas.

La función reintroductora sí se registra en el corpus, aunque también es escasa. Véase un ejemplo ilustrativo en (14):

(14) A Miguelito Dávila se lo llevó al Hospital Civil una ambulancia con los cristales pintados de blanco. Ø Había recuperado el conocimiento al pie de la escalera y a través de una cruz roja descascarillada que había pintada en la puerta trasera $\emptyset$ pudo ver unos rayos de sol que al traspasar la luz llenaban la ambulancia de una luz rosada y un poco irreal. $\emptyset$ Tuvo algún vómito y $\emptyset$ estuvo un poco desconcertado, pero su madre le cogía la mano y le repetía en voz baja su nombre. También lo 
tranquilizaba el tintineo de unos instrumentos médicos sacudidos suavemente dentro de una bandeja metálica, un tarro de cristal que rodaba en las curvas. (AS, 340)

En (14), el tópico $\underline{A}$ Miguelito Dávila inicia un párrafo en el que hay bastantes referencias subsiguientes a esa entidad. Ese personaje, que, por lo demás, es importante en la obra de A. Soler, no se ha mencionado en los dos párrafos que preceden a esa construcción de DI. El escritor utiliza, sobre todo al final de la novela, el recurso de la reintroducción para ir narrando lo que les sucedió a los personajes más destacados de su narración. Los ejemplos aparecidos en $(7 \mathrm{a}-\mathrm{b})$ ilustran también ese procedimiento.

A modo de conclusión se puede decir que las funciones introductoria y reintroductoria sí se registran en el corpus, aunque son muy poco frecuentes, sobre todo la primera.

\subsection{Continuidad temática}

La continuidad temática se refiere a las porciones de un discurso que giran alrededor de un determinado tópico. Según Hidalgo (2003: 271), esa función se caracteriza por presentar "continuidad referencial, continuidad temporal y presencia de ciertos marcadores discursivos y conjunciones que pueden indicar continuidad”. Martín Butragueño (2010: 172) encuentra que en su corpus hay un $45 \%$ de casos de continuidad ${ }^{33}$.

La continuidad temática es bastante frecuente en el presente corpus. Resulta fácil de observar por las referencias anteriores y posteriores a la entidad que funciona como tópico. Véanse al respecto los ejemplos (15a-b):

(15) a. Hay un hombre que vive enfrente, más allá de los árboles cuyas copas coronan el centro de esta plaza y exactamente a mi altura, un tercer piso, las casas inglesas no tienen persianas o raramente, si acaso visillos o contraventanas que no suelen cerrarse hasta que el sueño inicia sus cacerías atolondradas, y a este hombre lo veo bailando frecuentemente, alguna vez acompañado, pero casi siempre él a solas con gran entusiasmo recorriendo en sus danzas o más bien bailoteos el alargado salón entero, ocupa cuatro ventanales. $\emptyset$ No es un profesional que ensaye, en modo alguno, eso es seguro: $\emptyset$ suele estar vestido de calle, incluso a veces con corbata y todo, como si $\emptyset$ acabara de entrar por la puerta tras la jornada y su impaciencia le consintiera solo $\emptyset$ desprenderse de la chaqueta y $\emptyset$ arremangarse (pero la norma

\footnotetext{
${ }^{33}$ El autor, siguiendo a Hidalgo (2003), subdivide los casos de continuidad temática en incorporación, ampliación, colaboración y repetición.
} 
es que Ø vista jerseys elegantes o polos de manga larga o nikis de manga corta), y sus pasos de bailes son espontáneos... (JM, 49)

b. "Hombre, Bonaparte", le dijo a Rafi pasando por su lado, antes de preguntarle a Fina si estaba lista y le ayudaba a bajar la persiana metálica. Y como la otra le dijera que sí con una sonrisa, el Corbata, con mucha naturalidad le preguntó si al soldadito de plomo lo dejaban dentro o fuera de la tienda. A Rafi Ayala se le atragantaron en mitad del pecho todos los castigos que $\emptyset$ llevaba recibidos en el ejército, todas las arengas e instrucciones para el combate. Pero lo único que Ø hizo con toda aquella bola de sensaciones fue clavar su dedo indice en la espalda del Corbata, que se volvió y se quedó mirándolo a los ojos, muy cerca el uno del otro. [...]. Rafi Ayala los vio irse en la moto sin $\emptyset$ haber pronunciado ninguna palabra ni Ø haber hecho otro gesto que aquel del dedo en la espalda del periodista. Nada más perderse la moto tras la esquina, las palabras, la ira y la violencia volvieron de golpe a la boca y a la mente de Rafi Ayala. (AS, 104).

En (15a) la frase nominal inicial, un hombre que vive enfrente, tiene una considerable continuidad temática, demostrable por el número de referencias a esa entidad. Sin embargo, entre la primera mención y la DI se rompe ligeramente esa continuidad a causa de un comentario del narrador sobre la plaza y las casas inglesas ${ }^{34}$. Quizá esa es la razón por la que el escritor emplea una DI: para instar al lector a conectar el tópico de esa DI (a este hombre $)$ con un constituyente previo y prepararlo para la continuidad temática que sigue.

En (15b) hay dos casos de DI con tópicos que, además de remitir a la misma entidad

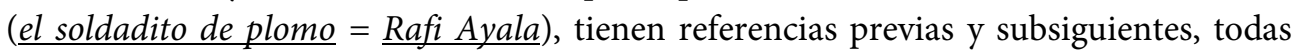
ellas en negrita.

\subsection{Cambio temático progresivo}

Según Hidalgo (2003: 248), el cambio temático progresivo "introduce un asunto relacionado con lo anterior pero que, al mismo tiempo, se desvía ligeramente del tema inicial o del referente objeto de la discusión". Este tipo de cambio implica modificaciones paulatinas: se va pasando de manera imperceptible de un (sub)tópico o a otro; puede ocurrir incluso que, después de varios (sub)tópicos conectados parcialmente entre sí,

\footnotetext{
${ }^{34}$ En futuros estudios convendría estudiar los casos, ilustrados en (8) y (15b), en los que hay alguna cláusula que interrumpe la continuidad temática. Es muy posible que esa interrupción favorezca el uso de la DI ya que esta construcción, de tópico marcado, estimula al receptor a hacer las conexiones discursivas apropiadas.
} 
el tópico del que se habla al final de la comunicación no tenga ya ninguna relación con aquel del que se hablaba al principio.

En el presente corpus no he encontrado casos de DI involucrados en un cambio temático progresivo. Puesto que sí los encuentran Hidalgo (2003: 247-260) y Martín Butragueño (2010: 172-173) en los corpus que analizan ${ }^{35}$, cabría pensar que esta función se da más en el español oral que en el escrito, pero esta afirmación debería ser confirmada o rechazada por futuras investigaciones

\subsection{Cierre temático}

En el presente artículo considero que hay cierre temático cuando el empleo de una DI da por concluido un (sub)tema del discurso ${ }^{36}$. Véanse dos ejemplos de cierre temático en (16a-b):

(16) a. Sentado en una silla de plástico, y con los pies metidos en agua, repartía unos prospectos que hablaban de las propiedades curativas de las hierbas. Los prospectos se los había dado otro viejo del Amoniaco. (AS, 49)

b. - Tengo novio.

Y que Rubirosa le contestó, con una sonrisa rara que se le metía dentro de la boca:

-Eso, viéndote, ya se lo imagina uno. Pero nos veremos otro día ¿verdad, Luli? (AS, 135)

En (16a), la DI en la que aparece el tópico los prospectos da por terminado un párrafo, y en el siguiente no se mencionan los prospectos, por lo tanto puede considerarse un caso de cierre temático. En (16b), la DI donde aparece como tópico el demostrativo $\underline{\text { Eso }}$ da por concluido un subtema discursivo, el de si Luli tiene novio. Esto se comprueba porque la cláusula que sigue (Pero nos veremos otro día) abre el camino a un nuevo subtema, el que plantea la posibilidad de que los personajes involucrados en el diálogo puedan verse en otra oportunidad.

En el corpus se registran varios casos de cierre temático, sobre todo cuando el tópico es el demostrativo $\underline{e s o}$, como en (16b).

\footnotetext{
${ }^{35}$ Martín Butragueño da un porcentaje de 23\%.

${ }^{36}$ Martín Butragueño encuentra sólo un 1\% de casos de cierre temático en su corpus.
} 


\subsection{Inciso}

Ningún autor hace referencia a esta función. Sin embargo, en la obra de J. Marías se dan varios casos de DI que constituyen incisos, comentarios al margen del hilo del discurso, como se muestra en (17a-b):

(17) a. Hasta el agua con que se habría peinado horas antes parecía no habérsele secado del todo (que usara fijador lo descartaba). Y alli sentado con aparente despreocupación podría todavía vérselo, (JM 101)

b....los dos últimos eran más del subgénero espías o así me sonaba -todos esos nombres los conocía asimismo a través de mi padre- luego había esperanzas de encontrar allí a Fleming, (JM, 164)

El autor suele marcar estos incisos por medio de paréntesis (17a) o de guiones (17b). El tópico de los incisos, como es natural, apenas tiene referencias adicionales, con excepción de la copia.

\section{Conclusiones}

El estudio de Dislocación a la izquierda, basado en dos obras de escritores españoles, ha permitido conocer mejor diversos aspectos discursivos de esa construcción.

Con respecto al tipo de información transmitida por el tópico, los datos del corpus indican que lo más frecuente es que éste contenga información evocada, aunque también hay tópicos que contienen información inferible. Los casos de información nueva son escasos y presentan características particulares.

$\mathrm{Al}$ analizar en el corpus las tres funciones discursivas atribuidas por Prince (1997) a la DI del inglés, se ratifican dos de esas funciones: función simplificadora y función de inferencia poset. No se registran casos de la tercera función, denominada amnistía de violación de una isla, lo cual seguramente se debe al carácter canónico de la escritura literaria. La función simplificadora, que en el presente trabajo se redenomina facilitadora del adecuado procesamiento del discurso, es bastante frecuente en el corpus, sobre todo cuando el tópico es un complemento directo léxico. Lo que justifica el empleo en español de una DI en ese tipo de contexto es que, gracias a esa construcción, se estimula al receptor a interpretar el complemento directo léxico como tópico y no ya como el foco o como parte del foco, que sería lo estadísticamente esperable.

Aunque apenas hay casos de DI para señalar contraste, sí se dan algunos ejemplos de tema comparativo, lo cual apunta a una de los posibles funciones de esa construcción. 
Con respecto al empleo de la DI en la estructura temática del discurso, lo más usual es hallarla en casos de continuidad temática. También se encuentra, aunque en grado reducido, en contextos de cierre temático y de inciso. El empleo de la DI para introducir o reintroducir un tópico es asimismo posible aunque escaso. En el corpus no se han encontrado construcciones de DI que indiquen cambio temático progresivo.

Algunos resultados de esa investigación se asemejan en mayor o menor grado a los de Hidalgo (2003) y Martín Butragueño (2010) para el español: i) lo más frecuente es que el tópico de la DI transmita información evocada; ii) el tópico de la DI tiene un uso muy reducido cuando se emplea para introducir o reintroducir un tópico, o bien para indicar contraste. Entre las diferencias observadas podemos señalar, por ejemplo, que mientras los mencionados investigadores sí encuentran casos de DI para marcar cambio temático progresivo, en el presente corpus no los hay.

De todos los factores discursivos estudiados en la presente investigación, parecen particularmente relevantes la relación (explícita o implícita) entre la entidad topicalizada y una información anterior, la función discursiva de la DI que aquí se ha denominado facilitadora del adecuado procesamiento del discurso, así como la contribución de esa estructura a la continuidad temática del discurso.

Recibido: 25-I-2011

Aceptado: 1-XI-2011

\section{Obras que componen el corpus}

Marías, Javier (2002): Tu rostro mañana. 1. Fiebre y lanza. Madrid, Santillana.

Soler, Antonio (2005): El camino de los ingleses. Barcelona, Ediciones Destino.

\section{Referencias bibliográficas}

Aijmer, K. (1989): "Themes and tails: the discourse functions of dislocated elements", Nordic Journal of Linguistics, 12, págs. 137-154.

Ashby, W. J. (1988): "The syntax, pragmatics and sociolinguistics of left- and rightdislocation in French", Lingua, 75, págs. 203-229.

Barnes, B. K. (1985): The pragmatics of left detachement in spoken standard French [Pragmatics \& Beyond]. Amsterdam, John Benjamins.

Bentivoglio, P. (1989): “Función y significado de la posposición del sujeto nominal en el español hablado". En Estudios sobre español de América y lingüística afroamericana (ponencia presentada en el 45 Congreso Internacional de Americanistas, julio de 1985). Bogotá, Instituto Caro y Cuervo, págs. 40-58. 
Chafe, W. (1976): "Giveness, contrastiveness, definiteness, subjects, topics and point of view”. En Li, Ch. (ed): Subject and topic. New York, Academic Press, págs. 25-55.

Chafe, W. (1994): Discourse, consciousness, and time. Chicago \& London, The University of Chicago Press.

Dik, S. C. (1978): Functional grammar. Amsterdam, North-Holland.

Geluykens, R. (1992): From discourse process to grammatical construction: On leftdislocation in English. Amsterdam \& Philadelphia, John Benjamins.

Givón, T. (1983): “Topic continuity in discourse: An introduction”. En Givón, T. (ed): Topic continuity in discourse: a quantitative cross-language study. Amsterdam \& Philadelphia, John Benjamins, págs. 3-41.

Givón, T. (1988): “The pragmatics of word-order: predictability, importance and attention". En Hammond, M., E. Moravcsik \& J. Wirth (eds): Studies in syntactic typology. Amsterdam \& Philadelphia, John Benjamins, págs. 243-284.

Givón, T. (1990): Syntax: A functional-typological introduction II. Amsterdam / Philadelphia, John Benjamins.

Gregory, M. L. \& L. A. Michaelis (2001): “Topicalizations and left-dislocation: functional opposition revisited", Journal of Pragmatics, 33, págs. 1665-1706.

Gutiérrez Ordoñez, S. (2000): Temas, remas, focos, tópicos y comentarios. Madrid, Arco / Libros.

Hidalgo Downing, R. (2003): La tematización en el español hablado. Madrid, Gredos.

Jiménez Juliá, T. (2000): “Tema en español y en inglés: dos conceptos enfrentados", Bulletin of Hispanic Studies, LXXVII, págs.153-176.

Lambrecht, K. (1998): Information structure and sentence form. Topic, focus and the mental representations of discourse referents. Cambridge, Cambridge University Press.

Lambrecht, K. (2001): "Dislocation”. En Haspelmath M. et alii. (eds): Language typology and language universals. An International Handbook, vol. 2. Berlín \& New York, Walter de Gruyter, págs. 1050-1078.

Manetta, E. (2007): "Unexpected left dislocation: An English corpus study", Journal of Pragmatics, 39, págs.1029-1035.

Martín Butragueño, P. (2008): “Aspectos prosódicos de la tematización lingüística. Datos del español de México”. En Herrera E. y P. Martín Butragueño (eds): Patrones sintácticos y variación. México, Colegio de México, págs.1-61.

Martín Butragueño, P. (2010): "La posición extrapredicativa del tema en la lengua hablada”. En Bogard, S. (ed): Semántica, pragmática y prosodia: reflejos en el orden de palabras en español. México, El Colegio de México, págs. 117-183.

Padilla García, Xose A. (2005): Pragmática del orden de palabras. Alicante, Universidad de Alicante. 
Prince, E. F. (1981): “Toward a taxonomy of given/new information”. En Cole, P. (ed): Radical pragmatics. New York, Academic Press, págs. 223-255.

Prince, E. F. (1985): "Fancy syntax and 'shared knowledge", Journal of Pragmatics, 9, págs. 65-81.

Prince, E. F. (1997): "On the functions of left-dislocation in English discourse". En Kamio, A. (ed.): Directions in functional linguistics. Amsterdam \& Philadelphia, John Benjamins, págs. 118-143.

Reinhart, T. (1982): "Pragmatics and linguistics: An analysis of sentence topics". Philosophica, 27, págs. 53-94.

Reyes, G. (1985): “Orden de palabras y valor informativo en español”, Philologica hispaniensia in honorem Manuel Alvar, vol II. Madrid, Gredos, págs. 567-588.

Sedano, M. (2011): “Algunas características formales de la dislocación a la izquierda en el español escrito”. En de Bustos, J. J. et alii (eds.): Sintaxis y análisis del discurso hablado en español. Homenaje a Antonio Narbona II. Sevilla, Universidad de Sevilla, págs. 923-941.

Silva-Corvalán, C. (1984): “Topicalización y pragmática en español”, Revista Española de Lingüística, 14, 1, págs. 1-19.

Snider, N. (2005): “A corpus of left-dislocation and topicalization": http://www.hlp. rochester.edu/ nsnider/pubs/qpfest05_talk.pdf (30-09-2010).

Traugott, E. C. (2007): "Old English left-dislocations: Their structure and information status”, Folia Linguistica, 41/3-4, págs. 405-441.

Vallduví, E. (1994): "Detachment in Catalan and information packaging", Journal of Pragmatics, 22, págs. 573-601.

Ziv, Y. (1994): "Left and right dislocations: Discourse functions and anaphora", Journal of Pragmatics, 22, págs. 629-645. 